\title{
Influence of the Thermal Conductivity of Air on the Moisture Homogeneity of a Tray Dryer
}

\author{
Esparza E. Jessica ${ }^{1}$, Grisales M.J. Felipe ${ }^{1}$, Pérez S.F. José ${ }^{1}$, Ordóñez S.L. Eduardoํ, Lobatón G.H. Fabián ${ }^{2 *}$ \\ ${ }^{1}$ Facultad de Ingeniería y Administración, Departamento de Ingeniería, Universidad Nacional de Colombia, Palmira Carrera \\ 32 \# 12 - 00, Palmira Valle del Cauca, Colombia, South America \\ ${ }^{2}$ Universitaria Agustiniana, Avenida Ciudad de Cali \#11b-95, Bogotá Cundinamarca, Colombia, South America
}

Corresponding Author Email: hugo.lobaton@uniagustiniana.edu.co

https://doi.org/10.18280/ijht.370138

Received: 15 January 2019

Accepted: 10 March 2019

\section{Keywords:}

computational fluid dynamics (CFD),

local values, mandarin, homogeneity, dryers

\begin{abstract}
The objective of this study was to identify the incidence of the local thermal conductivity of a fluid in a tray dryer by means of CFD simulation. In the experimental part, identical pieces of mandarin epicarp (Citrus reticulata) were dried at $40^{\circ} \mathrm{C}$ at two air inlet velocities $(3.5 \mathrm{~m} / \mathrm{s}$ and $5.5 \mathrm{~m} / \mathrm{s})$. For the simulations, equations of energy, continuity and momentum were used, which were solved with ANSYS software (Student v.19.2). The simulations showed spatial variations in the eddy viscosity and thermal conductivity of the air generated in the dryer, where higher experimental moisture values correspond to lower values of the eddy viscosity $(<0.0001 \mathrm{P} \times \mathrm{s})$ and thermal conductivity $\left(<0.45 \mathrm{~W} / \mathrm{m}^{2} \times \mathrm{K}\right)$. Therefore, this study proposes that in the design of tray dryers, the drying kinetics should be reported in values of the effective thermal conductivity, which must be homogeneous to ensure homogeneity in the product
\end{abstract}

\section{INTRODUCTION}

Colombia has been characterized as an agricultural country, producer of a variety of fruits and vegetables designed for local consumption or export. This activity is mainly concentrated in rural areas, where in some regions the roads and energy infrastructure are not adequate, leading to a reduction and accelerated deterioration of the produce's quality attributes. In addition to these factors, access to new and efficient conservation technologies is costly, limiting the options for farmers and their products.

Mandarins are a subtropical temperate climate species belonging to the family Rutaceae and genus Citrus [1]. The fruit is globose and uniformly orange in colour, with a sweet flavour, granulated peel and medium size. Colombia produces mandarins in departments such as Huila, Antioquia, Tolima, Cauca, Caldas, Valle del Cauca, Santander and Risaralda, which contributed to $20.25 \%$ of the national production for 2016 [2]. The food processing residues of this fruit have great potential as raw materials for commercial products because they contain large amounts of enzymes, flavonoids, essential oils and pigments [3]

Decreasing the moisture content and water activity (Aw) extend the useful life of products, significantly reducing the action of microorganisms and enzymes within the biological matrix [4]. Similarly, the reductions in costs associated with the supply chain, such as those for transportation and storage, are advantageous because less moisture means a lower product volume. Convection tray drying is the most common drying method for fruits, vegetables and medicinal plants in developing countries [5], and it is presented as an economically viable solution compared to other drying alternatives.

In Colombia, this technology has been applied in different products. Potosí-Calvache et al. optimized the drying process of a pumpkin at a temperature of $55{ }^{\circ} \mathrm{C}$ and an air flow of 7 $\mathrm{m} / \mathrm{s}$, where the minimum possible moisture content and the maximum concentrations of carotenoids and total phenols were obtained [6].

Many investigations of batch drying have focused on the effects of temperature and the air velocity at the dryer inlet as the main parameters that influence the drying quality, leaving aside the flow uniformity, which may be linked to design variables [7]. However, obtaining products with a uniform moisture content in a tray dryer is not common. Precoppe et al. [8] reported non-uniform moisture contents in dried litchi samples, with $12 \%$ in the lower tray and $38 \%$ in the upper tray. The authors used experimental techniques in conjunction with anemometers, thermometers and mini-manometers to record the internal data of the fluid inside the drying cabinet and to contrast them with the moisture data. Another study proved that non-uniform air flow decreases the homogeneity of the final moisture content of the samples, negatively affecting the energy efficiency of the dryer and increasing the total drying time [9]. Experimental methods of local velocity measurements, while providing real data, are expensive and often difficult to implement.

Numerous investigations have begun to use simulation techniques such as computational fluid dynamics (CFD) to evaluate the lack of homogeneity inside the dryers, considerably reducing the experimentation times in the proposed models without increasing the design costs $[5,7,9$ 11]. The CFD technique allows one to simulate and validate the internal behaviour of parameters that are difficult to access for measurement such as the air velocity and turbulence profiles in the drying chamber. Although CFD simulations have been successfully validated for tray dryers, there has not been a variable reported to date that relates the air turbulence to the solid matrix.

Most studies that use mathematical models, especially the investigations associated with the $k-\varepsilon$ model, usually address the effective thermal conductivity $\left(k_{e f f}\right)$ of the matrix 
to be dehydrated as a fixed variable, which is determined by the thermal conductivity of the fluid $\left(k_{f}\right)$ and the solid $\left(k_{s}\right)$, in addition to the porosity $(\psi)$. The effective thermal conductivity $\left(k_{e f f}\right)$ directly influences the drying temperature in the solid matrix and thereby the mass transfer of the solid into the air. This is exemplified in the model used by [12], where the drying air is related to the solid matrix.

Although this assumption of a constant fluid thermal conductivity facilitates the development of an accurate mathematical model, it may not be entirely correct to describe the complete geometry of the dryer because this parameter can vary spatially due to different magnitudes of turbulence. The objective of this study is to identify the incidence of the local thermal conductivity of air in a tray dryer by means of a CFD simulation. This variable is contrasted with experimental results of the moisture content of a mandarin peel in different dryer positions.

\section{MATERIALS AND METHODS}

\subsection{Materials}

Ripe Oneco mandarins were obtained from the Galeria Alameda supermarket in the city of Santiago de Cali (Valle del Cauca). The mandarins were washed with a soapy water solution at a ratio of 1:4, disinfected with hypochlorite at 100 ppm for 5 min and peeled. The epicarp (peel) of the mandarins was cut into julienne strips $2.8 \mathrm{~mm}$ thick and approximately $6.5 \mathrm{~cm}$ long, immersed in a metasulfite solution at $100 \mathrm{ppm}$ for $5 \mathrm{~min}$, blanched for $2 \mathrm{~min}$ at $85^{\circ} \mathrm{C}$ and frozen for subsequent dehydration.

\subsection{Instruments and equipment}

The drying cabinet in the unit operations laboratory of the National University of Colombia, located in the city of Palmira, Valle del Cauca, was used. The chamber dimensions are 128 $\mathrm{cm}$ high, $84 \mathrm{~cm}$ wide and $55 \mathrm{~cm}$ deep. The equipment has a turbine, a system of blades and a recirculating air duct. The air inlet is located in the lower part of the left side, and the outlet is in the upper part of the right side. There are 10 fixed trays inside, distributed at the top, with a distance between them of $10.49 \mathrm{~cm}$. The dimensions of these trays are $4.5 \mathrm{~cm}$ high and $0.6 \mathrm{~cm}$ thick, $50 \mathrm{~cm}$ wide and $50 \mathrm{~cm}$ deep. The equipment has an electronic panel that controls the temperature and the air inlet.

The turbine is responsible for transporting air from outside to inside by means of a duct that is connected to the entrance of the equipment. A system of resistances between the turbine and the entry point to the dryer increases the air temperature. There is a pair of fins for each tray, located on the sides. These fins are distributed in three sections (high, medium and low trays), allowing the distribution of the flow of air inside the chamber. The air flow was measured using an anemometer, while the moisture of the samples was obtained using a Precisa XM60 moisture balance, $\mathrm{e}=0.01$, Switzerland.

\subsection{Drying operation}

The inlet temperature to the dryer was $40^{\circ} \mathrm{C}$, with air velocities of 3.5 and $5.5 \mathrm{~m} / \mathrm{s}$. The drying time was $6 \mathrm{~h}$ for both experimental runs. The recirculation system was not taken into account for this test. The samples were distributed throughout the dryer on the trays, as shown in Figure 1. Before drying, the moisture content of the peels was measured in trays 1, 5 and 8 . At the end of $6 \mathrm{~h}$ of drying, the moisture was reported as the average values (measurements in triplicate) of the peels located in the centre of each tray studied (1,5 and 8), as shown in Figure 1.

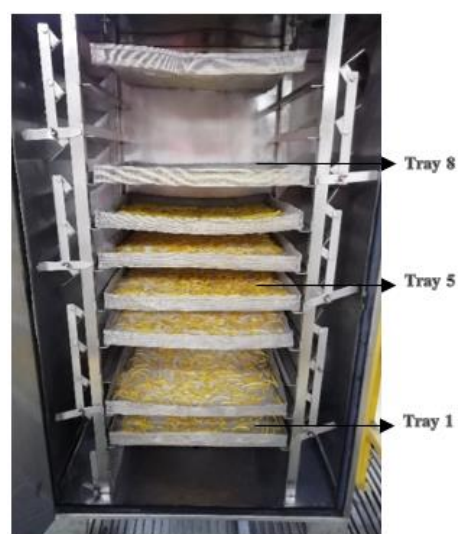

Figure 1. Distribution of mandarin peels.

Distribution of the trays from the bottom to the top of the convection dryer

\subsection{CFD simulation}

For the CFD simulations, the energy, continuity and momentum equations were taken into account to describe the air flow behaviour within the geometry. To model the turbulence, a $k-\varepsilon$ model was used, which comprises two equations with constants C1-epsilon of 0.142 and C2-epsilon of 1.68. For the boundary conditions, those previously described in the experimental section were used. The mesh of the drying equipment (Figure 2) consisted of 350,000 nodes. All the simulations were carried out in ANSYS software (Student v.19.2). The simulations were run until convergence was reached.

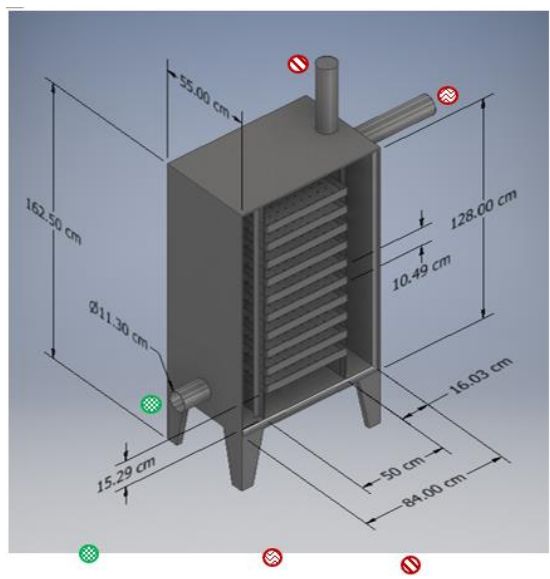

Figure 2. Three-dimensional model of the drying Cabinet. Air Inlet Air outlet to the environment, Recirculated air

\section{RESULTS AND DISCUSSION}

Table 1 shows the percentage of the final moisture reached in the drying of the mandarin peel. Here, it is observed that for the velocities of 3.5 and $5.5 \mathrm{~m} / \mathrm{s}$, the samples located in Tray 1 presented the greatest moisture loss compared to those of 
Trays 5 and 8 . In Tray 1 , for a velocity of $3.5 \mathrm{~m} / \mathrm{s}$, the final moisture readings were $5.25 \%$, while for a velocity of $5.5 \mathrm{~m} / \mathrm{s}$, the final values were $4.67 \%$. In general, Tray 5 presented a higher moisture content compared to Tray 8 and Tray 1, even with the increase in velocity.

It should be noted that the data recorded in Table 1 indicate that there is no homogeneous distribution of air flow within the dryer, and therefore the drying uniformity is compromised.

Normally, in CFD dryer simulations, the results are shown as velocity vectors in different planes of the [5, 7, 9-11]. For this study, they are represented in terms of the effective viscosity as a measure of the turbulence and thermal conductivity of the fluid.

Table 1. Moisture percentage as a function of the flow velocity and tray distribution

\begin{tabular}{|c|c|c|c|c|c|c|}
\hline \multirow{2}{*}{ Tray } & \multicolumn{6}{|c|}{ Air inlet velocity } \\
\cline { 2 - 7 } & \multicolumn{3}{|c|}{$3.5 \mathrm{~m} / \mathrm{s}$} & \multicolumn{3}{c|}{$5.5 \mathrm{~m} / \mathrm{s}$} \\
\hline 1 & $5.25 \%$ & \pm & 0.18 & $4.67 \%$ & \pm & 0.11 \\
\hline 5 & $23.20 \%$ & \pm & 5.8 & $13.97 \%$ & \pm & 0.2 \\
\hline 8 & $15.82 \%$ & \pm & 0.93 & $11.60 \%$ & \pm & 0.47 \\
\hline
\end{tabular}

*: Spatial configuration of individual trays

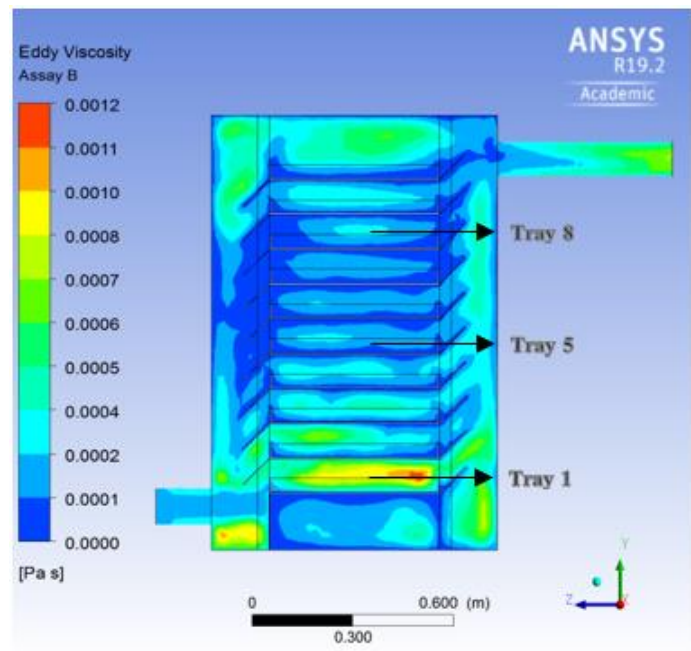

(a) $3.5 \mathrm{~m} / \mathrm{s}$

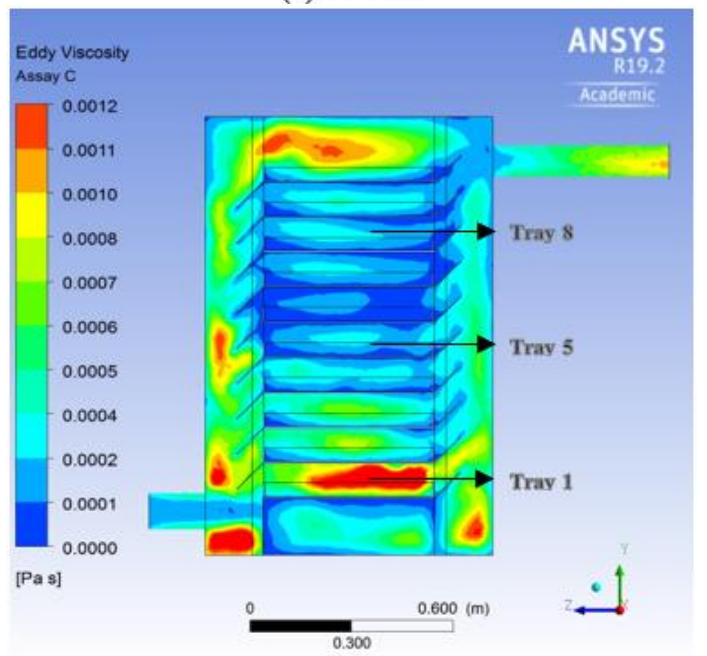

(b) $5.5 \mathrm{~m} / \mathrm{s}$

Figure 3. Eddy viscosity inside the dryer at different velocities

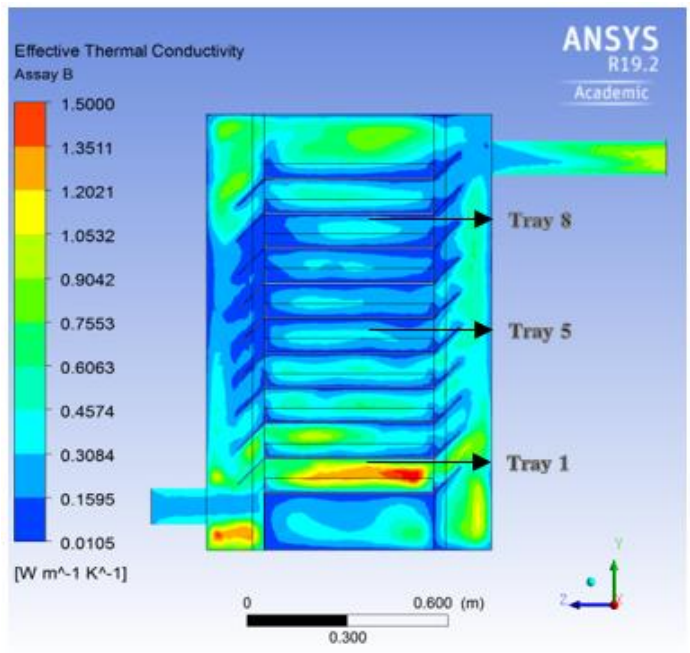

(a) $3.5 \mathrm{~m} / \mathrm{s}$

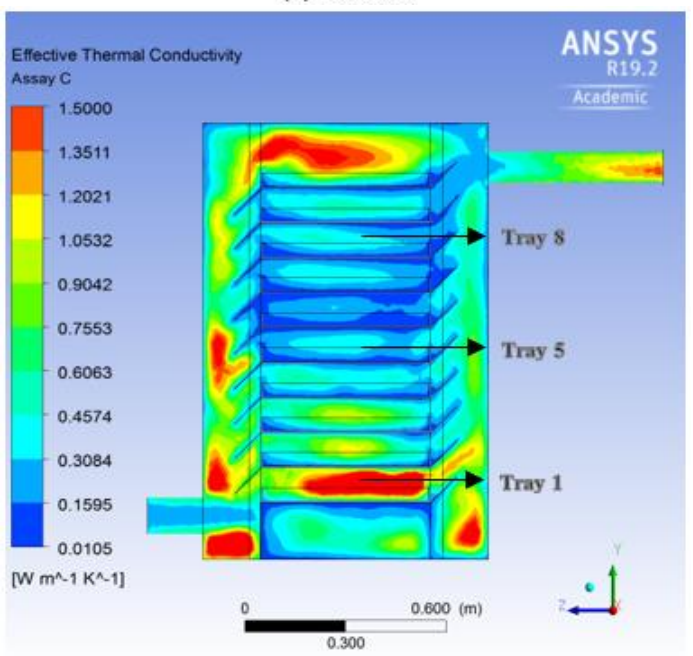

(b) $5.5 \mathrm{~m} / \mathrm{s}$

Figure 4. Effective thermal conductivity inside the dryer at different velocities

Figures 3 and 4 show a vertical plane that cuts the dryer axis in half. These planes show the contours of the eddy viscosity and thermal conductivity of the fluid at the exact point where the mandarin peels were collected.

According to Figures 3 and 4, when comparing the results of the eddy viscosity and thermal conductivity of the fluid in the simulations for velocities of 3.5 (a) and 5.5 (b) $\mathrm{m} / \mathrm{s}$, with the experimental data of the drying operation recorded in Table 1, it could be observed that in "Tray 1", where lower moisture percentages were obtained, higher values of these variables were predominant in comparison to the results obtained in Trays 5 and 8, where the values of these factors were rather low. Similarly, these graphs show that the increase in the air inlet velocity $(3.5-5.5 \mathrm{~m} / \mathrm{s})$ in the CFD simulations improves the distribution of these variables over the trays, covering a greater superficial area of the solid matrix, thus improving the internal drying conditions. This could be corroborated when observing the experimental results (Table 1) of the final moisture content for both Trays 5 and 8 , where the increase in velocity from 3.5 to $5.5 \mathrm{~m} / \mathrm{s}$ contributed to its reduction, even reaching more "homogeneous" values.

Turbulence models such as $k-\varepsilon$ seek to explain the formation of vortices dependent on the geometry of a flow domain and medium velocity gradients [13]. The fluid 
collision with walls and/or fittings generates pressure drops and energy losses, which generate a decrease in the formation of vortices and thereby a decrease in the thermal effectiveness of the fluid, which directly depends on the formation of turbulence in the dryer [14]. The increase in the inlet velocity generates an increase in the number of eddies (eddy viscosity) inside the cabinet, and with this, a general increase in the thermal effectiveness of the fluid. However, due to the dryer fittings, at both air inlet velocities, a non-homogeneity in both variables is noted.

In the case of Tray 1, the same reduction pattern in the final moisture content with the increase in the flow rate was observed; however, this difference was not as significant as in the trays, which may be related to the extraction limits of the free water. This implies that for the drying of this matrix, increases in the eddy viscosity above $0.001 \mathrm{P} \times \mathrm{S}$ and in the fluid thermal conductivity above $1.3 \mathrm{~W} / \mathrm{m}^{2} \times \mathrm{K}$ do not have considerable effects on the drying time since beyond a moisture content of $5 \%$, the bounded water would start controlling the process.

The importance of the effective thermal conductivity $\left(k_{\text {eff }}\right)$ is that it directly affects the temperature of the solid matrix, and this in turn affects the mass transfer (moisture removal), as shown by the following equations 1 and 2, developed in the study of [12].

$$
\begin{aligned}
& \left(\rho C_{p}\right)_{e f f} \frac{\partial(T)}{\partial t}=k_{e f f}\left(\frac{\partial^{2} T}{\partial x_{j}^{2}}\right) \\
& \psi \frac{\partial(C)}{\partial t}=D_{e f f}\left(\frac{\partial^{2} T}{\partial x_{j}^{2}}\right)
\end{aligned}
$$

where $\psi$ is the porosity, $D_{\text {eff }}$ the effective diffusivity, $C_{p}$ the specific heat capacity, $T$ the temperature and $C$ the concentration of water in the solid matrix.

The effective thermal conductivity (equation 3 ) is composed of the thermal conductivity of the fluid $k_{f}$ and the thermal conductivity of the solid $k_{s}$.

$k_{e f f}=k_{f} * \psi+(1-\psi) * k_{s}$

As shown in this study, the thermal conductivity of the fluid $k_{f}$ cannot be treated as a spatial constant, and it must be included in the drying models as a variable that depends on (x, $\mathrm{y}, \mathrm{z}$ ), as shown in Eq. 4

$k_{\text {eff }}=k_{f}(x, y, z) * \psi+(1-\psi) * k_{s}$

To find the values of $k_{f}(x, y, z)$, this study proposes to use CFD tools, and later these data can be coupled with the heat transfer and mass transfer models of the solid matrix to finally predict the spatial non-homogeneity in the moisture content of the samples.

\section{CONCLUSIONS}

When contrasting the results obtained in the drying process with the data of the different CFD simulations, it was corroborated that the eddy viscosity values and in turn the thermal conductivity of the fluid explain the behaviour of the moisture content of the samples. For the drying of mandarin peels, an eddy viscosity value of $0.001 \mathrm{P} \times \mathrm{s}$ and a fluid therma conductivity of $1.3 \mathrm{~W} / \mathrm{m}^{2} \times \mathrm{K}$ are proposed, which based on the dryer design must be spatially homogeneous. Future investigations should be aimed at the design of tray dryers based on optimum minimum values of the thermal effectiveness of the fluid, but with such values being homogeneous in the dryer. This would help to reduce the energy consumption of this type of equipment and ensure a uniform moisture distribution in the final product.

\section{REFERENCES}

[1] Tanaka T. (1954). Species problem in Citrus: A critical study of wild and cultivated units of Citrus, based upon field studies in their native homes. Revisio Aurantiacearum IX. Japanese Society for the Promotion of Science, Tokyo, p.152.

[2] Agronet. (2018). Agronet: ministerio de agricultura y desarrollo rural de Colombia, análisis -estadísticas, Mandarina. www.agronet.gov.co, accessed on Feb. 5, 2018

[3] Satari B, Karimi K. (2018). Citrus processing wastes: Environmental impacts, recent advances, and future perspectives in total valorization. Resources, Conservation and Recycling 129: 153-167. https://doi.org/10.1016/j.resconrec.2017.10.032

[4] Sanghi A, Ambrose RPK, Maier D. (2018). CFD simulation of corn drying in a natural convection solar dryer. Drying Technology 36(7): 859-870. https://doi.org/10.1080/07373937.2017.1359622

[5] Román F, Strahl-Schäfer V, Hensel O. (2012). Improvement of air distribution in a fixed-bed dryer using computational fluid dynamics. Biosystems Engineering 112(4): 359-369. https://doi.org/10.1016/j.biosystemseng.2012.05.008

[6] Potosí-Calvache DC, Vanegas-Mahecha P, MartínezCorrea HA. (2017). Secado convectivo de zapallo (Cucúrbita moschata): Influencia de la temperatura y velocidad de aire sobre la difusividad efectiva de humedad, contenido de carotenoides y fenoles totales. Dyna 84(202): 112-119. https://doi.org/10.15446/dyna.v84n202.63904

[7] Amjad W, Munir A, Esper A, Hensel O. (2015). Spatial homogeneity of drying in a batch type food dryer with diagonal air flow design. Journal of Food Engineering 144: $148-155$ https://doi.org/10.1016/j.jfoodeng.2014.08.003

[8] Precoppe M, Janjai S, Mahayothee B, Müller J. (2015). Batch uniformity and energy efficiency improvements on a cabinet dryer suitable for smallholder farmers. Journal of Food Science and Technology 52(8): 4819-4829. https://doi.org/10.1007/s13197-014-1544-y

[9] Ryu JB, Jung CY, Yi SC. (2013). Three-dimensional simulation of humid-air dryer using computational fluid dynamics. Journal of Industrial and Engineering Chemistry 19(4): https://doi.org/10.1016/j.jiec.2012.11.029

[10] Vargas, Caicedo, Martínez-Correa, Lobaton. (2018). Drying uniformity analysis in a tray dryer: An experimental and simulation approach. Advance Journal of Food Science and Technology 15: 233-238. https://doi.org/10.19026/ajfst.15.5901

[11] Amanlou Y, Zomorodian A. (2010). Applying CFD for designing a new fruit cabinet dryer. Journal of Food 
Engineering 101(1): 8-15. P Pressure

https://doi.org/10.1016/j.jfoodeng.2010.06.001 T $\quad$ Temperature

[12] Lemus-Mondaca RA, Vega-Gálvez A, Zambra CE, $\quad C_{p} \quad$ Specific heat capacity, J.kg-1 $\mathrm{K}^{-1}$ Moraga NO. (2017). Modeling 3D conjugate heat and C Water concentration mass transfer for turbulent air drying of Chilean papaya in a direct contact dryer. Heat and Mass Transfer 53(1): 11-24. https://doi.org/10.1007/s00231-016-1799-0

[13] Malekjani N, Jafari SM. (2018). Simulation of food drying processes by Computational Fluid Dynamics (CFD); recent advances and approaches. Trends in Food Science \& Technology 78: 206-223. https://doi.org/10.1016/j.tifs.2018.06.006

[14] Wu Y, Yu S, Zuo L. (2019). Large eddy simulation analysis of the heat transfer enhancement using selfoscillating fluidic oscillators. International Journal of Heat and Mass Transfer 131: 463-471. https://doi.org/10.1016/j.ijheatmasstransfer.2018.11.070

\section{NOMENCLATURE}

\section{Greek symbols}

$\psi \quad$ Porosity

\section{Subscripts}

$\begin{array}{ll}\text { eff } & \text { Effective } \\ \mathrm{f} & \text { Fluid } \\ \mathrm{s} & \text { Solid }\end{array}$

\section{Drying cabin}

$\begin{array}{ll}\otimes & \text { Cabinet. Air Inlet } \\ \otimes & \text { Air outlet to the environment } \\ \otimes & \text { Recirculated air }\end{array}$

